\title{
Deliberation and Automaticity in Habitual Acts
}

\author{
Christos Douskos \\ ORCID: https://orcid.org/0000-0002-1776-1100 \\ (Hellenic Open University, cidou@upatras.gr)
}

\section{Introduction}

Most current philosophers and psychologists assume that habitual acts do not ensue from deliberation, but are direct responses to the circumstances: habit essentially involves a variety of automaticity. My objective is to show that this view is unjustifiably restrictive. I argue that a habit can explain an act in various ways. Pointing to the operation of automaticity is only one of them. The view that habitual acts do not ensue from deliberation unduly narrows the explanatory scope of the idea of habit.

In section [2] I introduce a skeletal conception of habit that implies minimal commitments, and a corresponding conception of habit explanation. I suggest that the commitments of this minimal conception are generally acknowledged by accounts of habit in philosophy and psychology. This will enable me to use this conception as the basis of the ensuing discussion. In section [3] I turn to the notion of automaticity. Many philosophers, as well as the overwhelming majority of psychologists, assume that automaticity is an essential feature of habitual acts. However, the term 'automaticity' can be understood in very different ways, so I go on to examine how the variety of automaticity pertaining to habitual acts is best characterized. Habitual acts are commonly taken to be direct responses to the circumstances one is confronted with; the relevant kind of automaticity involves the absence of deliberation. I call the claim that habitual acts necessarily involve automatic processes of this kind(s) the Received View. In section [4] I argue against the Received View. I present certain sorts of contrast case, on the basis of which I argue that automaticity is not an essential feature of habit: habit can explain how an act came about in various ways, some of which do not imply the absence of deliberation. The discussion suggests that acquired automaticity is one outgrowth of habituation that is relevant to 
explanation, but not the only one. I conclude that the Received View fails to do justice to the theoretical usefulness of the idea of habit.

\section{Habit and Habit Explanation}

'Habit' and its etymological progenitors (habitus, hexis) have a long philosophical history, and have come to express a range of quite different ideas. These range from simple compulsions and additions to full-blown character traits, including all sorts of things in between, such as regularity and consistency of behaviour in certain circumstances, routine everyday activities, and much more besides. It is very doubtful whether one can formulate a conception of habit that is broad enough to encompass all these different ideas, while at the same time rigorous enough so as to be theoretically useful. In pretheoretical discourse we use 'habit' mostly in connection to repeated everyday activities, which do not ensue from compulsions or physiological addictions, but do not amount to full-blown character traits either. We shall see that this comes closer to fixing on a theoretically useful idea, as long as we impose a further restriction to the effect that habit is a determinant of action: habit explains acts, it is not merely regularity in behaviour.

On a quite skeletal characterization of habit found in current philosophical literature, habit is an agential disposition or propensity to do something in certain circumstances, a disposition acquired by having regularly done the same thing in similar circumstances in the past (Brett 1981, 363; Alvarez 2010, 187). This suggests three necessary conditions on the idea of habit: $S$ is in the habit of $a$-ing in circumstances $c$, only if (i) $S$ is disposed to undertake to $a$ when $c$ obtain; (ii) $S$ has $a$-ed in $c$ in a sufficient number of occasions in the past; (iii) the disposition to $a$ in $c$ is acquired as a result of having repeatedly $a$-ed in $c$ in the past. ${ }^{1}$ The central question to be addressed below is whether habit is subject to some additional condition: automaticity. Notice, however, that I am not looking for a set of sufficient conditions here, i.e. for a definition of habit, partly for the reasons given in the previous paragraph.

Let me briefly explain the import of these conditions. Condition (i) pertains to the

1 Let me explain the action-theoretic terminology used in these clauses and below. According to the coarse view of action individuation adopted here, actions are temporal particulars (events or processes) that can be variously specified. An action specification corresponds to a property, or to a thing one does in acting. Actions are intentional only under some specification(s). Similarly, an action can be a manifestation of a habit only under some specification(s) (Pollard 2008, 49). The fact that John is in the habit of taking a certain route when coming back from work does not imply that the lower-level specifications of his action on two or more occasions are the same; e.g. he will take a different lane, change gears at different points etc. So 'is habitual' is a predicate of action specifications: the schematic letters ' $a$ ' in the clauses above stand for properties or doables. It follows that 'ensues from deliberation' and 'ensues from automaticity' are also predicates of action specifications (on this last point, see $\mathrm{Wu} 2011$; 2013). Moreover, the same thing done (action specification) might ensue from deliberation on one occasion while from the operation of automaticity on another occasion. (This is a standard point in the literature on basic acts; Hornsby 1980, 69 and Enc 2003, 54). So just as 'is basic', 'ensues from automaticity' predicates thing done on occasion (or action-particulars under some specification). So I shall use 'act' as equivalent to 'thing done on occasion', for this allows me to talk simply of acts as exhibiting automaticity. 
explanatory role of habit. A habit ascription explains an agent's doing something on a certain occasion. We may explain why John is taking a certain route now that he is coming back from work as opposed to some other, by citing his habit of taking that route when he comes back from work. In this respect habit ascriptions have the same role as ascriptions of typical physical dispositions: we may explain why this rubber ball expanded after having been compressed on some occasion by citing a relevant disposition: its elasticity. ${ }^{2}$ Moreover, just as with typical dispositions, the canonical specification of a habit has to mention the circumstances of manifestation. This is because it is the fact that certain circumstances obtain on some occasion that explains why the habit in question has been manifested on that occasion. ${ }^{3}$ The fact that John is coming back from work now explains why he is taking that route. This is why the circumstances of manifestation are part of the identity conditions of a habit. John's habit of taking the bus when coming back from work is a different habit from the habit of taking the train when coming back from work, because only the latter habit can explain why John is boarding the train now that he is coming back from work. A habit cannot be specified merely as a habit of $a$-ing, for this would fail to explain why the agent $a$-ed on some occasion where $c$ obtained, as opposed to some other where $c$ did not obtain.

Two points are in order here. First, circumstances of manifestation do not always figure explicitly in habit ascriptions. In many cases the circumstances may be too diverse, or too generic. In such cases the circumstances cannot be specified in a non-trivial manner, and hence are likely to be omitted for pragmatic reasons. Second, the examples above already imply that 'circumstances' here is to be broadly construed: it does not include only the external environmental circumstances that elicit an act, as for instance the habit of picking up the phone when it rings. An agent's objectives, or the activity one is already engaged in, may also constitute the circumstances where one habitually takes certain means: John's objective is to get back home from work, and this constitutes the circumstances where he takes a certain route. In the latter case the habit of $a$-ing in $c$, can be specified equivalently, as a habit of $b$-ing by $a$-ing, since $b$-ing here is the circumstances where one $a$ 's. We may call habitual routines those cases where the habit elicits at least one means or step. Habitual routines often comprise multiple acts in a sequence; think of the different turns John takes when driving back home via the familiar route, or of making a cup of tea.

The second condition captures another central feature of habit. One cannot be in the habit of $a$-ing in $c$ unless she has repeatedly $a$-ed in $c$ in the past. As Pollard $(2008,46-47)$ explains, the claim that one is in the habit of doing something she has never done before

2 Notice that just as with other dispositions, a habit is not invariably manifested when the relevant circumstances obtain. So the modal force of a habit ascription ' $S$ is in the habit of $a$-ing' is not that of a conditional 'if $c$ obtain, $S$ a's'. The ascription is best paraphrased by a habitual sentence ' $S a$ 's in $c$ ', as opposed to a universally quantified proposition. Fara (2005) argues that this is true of disposition ascriptions generally.

3 As I mention below, the fact that certain circumstances obtain is (typically) the agent's reason for acting. 
(or does for the very first time) is not intelligible, because it involves a contradiction. Habit requires past repetition, as matter of conceptual necessity. However, the number of repetitions required to ascribe a habit varies widely depending on the habit in question, and even if we fix on a given habit, the answer is bound to be vague. Notice again that repeated performance does not suffice to ascribe a habit. One needs to have repeatedly done the same thing in relevantly similar circumstances. John is not in the habit of going to work by bus no matter how many times he commuted to work by train.

It is the third condition that raises the most controversial questions, however. This condition in effect joins conditions (i) and (ii): it requires that the disposition in question is formed as a result of repeatedly acting in the same way in similar circumstances. It is surely a central fact about human nature that by repeatedly acting in a certain way in certain circumstances we acquire the relevant tendency, disposition or propensity. Indeed, it is well known that upon having acquired a habit, this habit can be manifested even when one has decided or resolved not to do the thing in question, as in the case of habitual action slips, where an agent acts contrary to one's previously formed intentions. ${ }^{4}$ Moreover, we all know that some habits are hard to break. We all have various 'bad' habits we repudiate and try to get rid of. But these facts about human nature require explanation. It is here that the idea of acquired automaticity becomes highly relevant. On the Received View, the propensity that constitutes a habit is grounded solely on the workings of a certain kind of automaticity: when one is in the habit of $a$-ing in $c$, one has the propensity to $a$ in $c$ to the extent, and only to the extent, that he responds by $a$-ing without any conscious thought or deliberation about what to do. I shall come back to this in what follows.

The basic characteristics of the idea of habit outlined above are also found in psychological research on habitual action. It is true that due to the behaviorist associations of the dispositional idiom in psychology, nowadays psychologists do not generally characterize habits as propensities or tendencies. (One exception is Quellette and Wood [1998, 55] who characterize habits as "tendencies to repeat responses given a stable supporting context"). This stands in sharp contrast with the philosophical tradition, in which the broader idea of habitus is a paradigm case of a dispositional notion. Nevertheless, I think that several characterizations of habit in psychology appeal implicitly to modal notions, or at least that they can be suitably re-phrased in a dispositional idiom without any change of substance. What I want to stress here is that psychologists also characterize a habitual act as a direct response to specific circumstances, and assume that a habit is formed on the basis of repeatedly acting in the same way in the past in these circumstances. For example, Wood and Neal $(2007,845)$ claim "habits are repeated responses that come to be cued by recurring features of contexts". Gardner, de Bruijn and Lally $(2011,175)$ formulate the idea of habit as "behavioural patterns learned through

4 For influential discussions of action slips in psychology, see Norman (1981) and Reason (1990). For discussion of the philosophical problems raised by slips see Amaya (2013). 
context dependent repetition: repeated performance in unvarying settings reinforces context-behaviour associations such that, subsequently, encountering the context is sufficient to automatically cue the habitual response". For Verplanken and Wood (2006, 91) habit is "[a] type of automaticity in responding that develops as people repeat actions in stable circumstances (...) Recurring aspects of performance circumstances come to trigger habitual responses directly without input from people's intentions or decisions to act". Orbell and Verplanken $(2010,374)$ assert that "[d]ifferent accounts of habit converge on the idea that three aspects of habit are central: a habit is behavior that is frequently repeated, has acquired a high degree of automaticity, and is cued in stable contexts". Gardner $(2015,279)$ lists eight definitions of habit in current literature. All but one explicitly post that habitual acts are elicited ('triggered', 'cued') by similar circumstances ('stable contexts', 'unvarying settings', or 'recurrent features of the context' or 'stable circumstances'). Notice finally that psychologists have long recognized that 'circumstances' or 'context' is to broadly construed, to account for habitual routines. ${ }^{5}$ Thus despite some terminological differences, these formulations of the idea of habit converge on the conditions outlined above: a habit is formed on the basis of repeated responses to similar circumstances, circumstances that directly elicit an act and thus explain why the habit has been manifested in some occasion.

In the next section I shall focus on another key element, which figures already of the characterizations above: the notion of automaticity.

\section{Habit and Automaticity: The Received View}

Until quite recently, the term 'automaticity' did not figure prominently in the philosophical literature on habit. In a classic discussion, Ryle (1949) claims that " $[\mathrm{w}] \mathrm{hen}$ we describe someone as doing something by pure or blind habit, we mean that he does it automatically and without having to mind what he is doing" (Ryle 1949, 30). But Ryle uses the term rather prosaically (as a "metaphorical title", as he puts it $[1949,95]$ ), and does not pause to consider its possible meaning. More recently, Julia Annas has no much use for this term in her discussion of habit as routine (Annas 2011a; 2011b). But this does not mean that the idea of automaticity is not pervasive in these discussions. For as we shall see, automaticity is best understood as an umbrella term for combinations of features such as the absence of deliberation and forethought, diminishing conscious awareness, or diminishing attention. And hardly any philosopher who has written on habit, or at least on habit as understood nowadays, has failed to notice these characteristics of habitual acts. Notice how Ryle alludes to the absence of attention in the quotation above, for instance.

5 This is usually formulated as the claim that (the automaticity of) habit guides "routine action sequences". See Bargh and Gollwitzer (1994, 78); Cooper and Shallice (2006); Wood and Neal (2007, 851); Graybiel (2008, 361); Gardner (2014, 280); As Wood and Rünger (2016, 292) notice, many psychologists claim that the sequencing of multiple acts is a distinguishing feature of the automaticity of habit (e.g. Dezfouli, Lingawi \& Balleine 2014). 
Two authors who have more to say on the idea of automaticity in their discussion of habit are Nathan Brett and Bill Pollard. After carefully distinguishing between the claim that an act is initiated automatically as a direct response to a cue or circumstances and the claim that automaticity guides the performance of the act, Brett (1981) subscribes to the idea that habitual acts are initiated or elicited automatically. And he takes the operation of automaticity to imply that the act is "not the product of a conscious decision", which is tantamount to saying that it involves the absence of deliberation (Brett 1981, 357; see also 364). The idea of automaticity is given a more prominent place in Bill Pollard's definition of habitual behavior (Pollard 2008, 55-56; Appendix: Summary of Definitions). Pollard builds automaticity in his definition of habit, only in the sense that habitual acts are elicited automatically as a response to the circumstances (Pollard 2008, 61), and the absence of deliberation in his definition of automaticity. ${ }^{6}$

Psychologists present a more united front in taking automaticity to be a defining feature of habit. Indeed, the two ideas came to be so closely connected that, as Wood and Rünger $(2016,292)$ observe that the term 'automaticity' is often used interchangeably with 'habit' in psychology literature. However, in psychology the term 'automaticity' is understood in very different ways. Since Bargh's $(1989 ; 1994)$ influential criticisms of earlier monolithic conceptions of automaticity (as for instance Schneider and Shiffrin 1977), the term 'automaticity' is not taken to stand for a single concept. On the influential de-compositional approach to automaticity (Moors \& De Houwer 2006; 2007), different varieties of automaticity are distinguished by appeal to the different combinations of features that characterize automatic processes. Among the most commonly cited features of automaticity are (i) the absence of deliberation and (its issue) intention; (ii) diminishing attention and the accompanying subjective sense of effort; (iii) diminishing (conscious) awareness; (iv) speed, accuracy and efficacy in overt bodily acts or other kinds of response. The key idea in de-compositional approaches is that different combinations of these features give different kinds or determinate concepts of automaticity. These varieties are exhibited in different kinds of automatic behavior.

Which combination or combinations of features pertain to the variety or varieties of automaticity exhibited in habitual acts? A survey of the relevant literature provides no univocal answer to this question. However, this does not matter for present purposes. What matters here is that there is general agreement in the literature that the automaticity of habit involves feature (i): the absence of deliberation and intention. Just as in the case of philosophers such as Brett and Pollard, psychologists take the absence of deliberation

6 Pollard's definition of habit consists of three clauses. A behaviour of $a$-ing in $c$ is a habitual action if (a) the agent has repeatedly $a$-ed in $c$ in the past; (b) $a$-ing in $c$ has become automatic for the agent as a result of this repetition; (c) the agent has rational intervention control over her habitual act. Pollard further defines the idea of automaticity figuring in (b) by two conditions: (i) the absence of conscious deliberation; (ii) the absence of trying (Pollard 2008 Appendix: Summary of Definitions). For a criticism of Pollard's views on habit see [author b]. 
to be a necessary (though not sufficient) condition of the automaticity of habit, and automaticity a necessary condition on habitual acts. ${ }^{7}$

This raises the question of what is meant by 'deliberation' in these discussions of automaticity. This question is not usually addressed, and when it is, the answers diverge to a smaller or larger extent. It is clear, however, that since deliberation is contrasted with automaticity, a rather exacting conception of deliberation is in play. Some philosophers would allow for some variety of more or less unconscious or implicit deliberation, which operates below the agent's awareness and does not demand resources of attention. They suppose that allowing for such a conception of deliberation is necessary to account for aspects of overt rational behavior that is not preceded by conscious thought. I believe that recourse to such a conception of deliberation testifies an intellectualist prejudice, but this is not the point here. My point is rather that since diminishing (conscious) attention and awareness are par excellence features of automaticity, this alleged variety of deliberation can no longer be contrasted with automaticity. Bearing this in mind, I shall take deliberation to be a conscious intentional activity, in which the agent aims to resolve a question. ${ }^{8}$ Deliberation is conscious in that it involves attention and awareness. Moreover, deliberation is an activity one intentionally engages in; it is impossible to deliberate unintentionally. Practical deliberation aims to resolve a practical question: what to do and/or how to do something. The questions addressed in practical deliberation are settled with the formation of intention, that is, the agent's decision about what to do and/ or how to do it.

The claim that a habitual act essentially involves automaticity and that this variety of automaticity implies the absence of deliberation is considered to be a consequence of the claim that habitual acts are directly 'activated', 'triggered' or 'cued' by the circumstances (broadly construed). The idea is that when an agent is in the habit of $a$-ing in $c$, the perception of $c$ elicits an act of $a$-ing without conscious thought or deliberation-which is to say that it elicits this response automatically. Indeed, in a widespread experimental research paradigm, the measure of the influence of the automaticity of habit in behavior ("habit strength") is its potential to elicit acts that conflict with one's intentions: action slips. Orbell and Verplanken $(2010,378)$ explain the rationale: given that a habitual act

7 Some examples: Ouellette and Wood (1998, 55); Verplanken and Wood $(2006,91)$; Graybiel (2008, 361); Neal and Wood (2009, 580); Gardner, Abraham, Lally, and de Bruijn (2012, 1); Gardner (2012, 33); Wood, Labrecque, Lin and Rünger (2014). For dissent, see Maddux (1997). Of course, this does not mean that the automaticity of habit is specified solely on the basis of this feature. Many authors follow William James $(1981,114)$ in citing diminishing attention and awareness as central features of the automaticity of habit. As Ouellette and Wood $(1998,55)$ observe, there is general agreement that the automaticity of habit involves diminishing attention (see also Graybiel 2008, 361; Wood, Labrecque, Lin \& Rünger 2014, 378-79). Other definitions often figure the feature of (diminishing) awareness, rather than attention (van t'Riet, Sijtsema, Dagevos and de Bruijn 2011, 586; Nilsen, Roback, Broström, \& Ellström 2010, 1). Nevertheless, the absence of deliberation and intention is a central feature of automaticity if only because, as I explain in the following paragraph, conscious deliberation implies other features, such as attention and awareness, whereas the converse is not the case.

8 I borrow the essentials of this characterization from Owens (2008). 
is elicited by contextual cues as opposed to intentions, we can measure the strength of the habit in question by "the likelihood of an individual making an unintended response to a cue previously associated with that response. The stronger the cue contingent automaticity associated with the response, the more likely an accidental, nonintentional response would be made." Similarly, in their comprehensive review article of the psychology of habit, Wood and Rünger $(2016,292)$ say that "[t]wo defining features of habit automaticity are (a) activation by recurring context cues and; (b) insensitivity to short-term changes in goals (a.k.a., not goal dependent)." These two features are closely related: it is because a habitual act is activated by a context cue that it is insensitive to one's current goals. And since intentions, the issue of deliberation, are commonly taken to be a kind of goal (Moors \& De Houwer 2006, 303, inter alia), the claim that habitual acts are not goal-dependent is precisely the claim that they satisfy the feature (i) of automaticity: the absence of deliberation and its issue, intention.

Not all psychologists would agree that the automaticity of habit is not a form of goal-dependent automaticity. An alternative view appeals to the 'auto-motive' model of goal-dependent action (Bargh 1990; 1997; Bargh \& Gollwitzer 1994), on which agential goals can be activated by being directly elicited by environmental circumstances or other features of the context. Thus Aarts and Dijksterhuis (2000a; 2000b) have argued that, when an agent is in the habit of $a$-ing by taking certain means $b$, forming an intention to $a$ automatically elicits the goal to $b$ (a habitual routine). But notice that this model in no way implies that the automaticity of habit involves deliberation and intention. On the contrary, the claim that the goals in question are automatically activated is a claim to the effect that the process by which these goals are formed does not involve deliberation, attention or (perhaps) even awareness. So it does not issue in intentions proper, but only in a variety of goals which fall short of intentions proper. One of the theoretical incentives for this model is to accommodate the notion that habitual acts can exhibit a form of goal-directed automaticity while not ensuing from conscious deliberation and intentions. ${ }^{9}$

In this section we have seen that many philosophers and almost all psychologists take automaticity to be a defining feature of habitual acts. Habitual acts are direct

9 One might wonder how the claim that habitual acts ensue from automaticity squares with the fact that in the explanation and assessment of action we commonly take manifestations of habit to be things intentionally done. Though it is not necessary to argue for this here, I should like to point out that this problem arises only if one assumes the Causal Theory of Action. On this theory, an event is an action only if it is suitably caused by mental states, and it is an intentional action only under the specification figuring in the content of these states. In a nutshell, the problem is that since habitual acts can ensue from the operation of automaticity (here it not does not matter whether they always do), and the operation of automaticity is contrasted with the causal operation of mental states, habitual acts can hardly be intentional or indeed manifestations of agency at all. This is why, as several authors have argued (Pollard 2006a; Di Nucci 2011; [author a]), the Causal Theory cannot accommodate the intentional, or even agential, character of habitual acts. However, the problem dissolves on a conception of reasons as facts. When one manifests a habit of $a$-ing in $c$, the fact that $c$ obtain (typically, at least) constitutes the agent's reasons for $a$-ing. The fact that John is getting back home is his reason for taking that route. The fact that the phone rings is one's reason for reaching for the handset. Habitual acts are elicited by the circumstances that provide one's reason for acting, and are explained by the fact that these circumstances obtain in the way(s) facts rationally explain an act. 
responses to circumstances, which is to say that the relevant variety of automaticity involves the absence of deliberation and intention. Given its wide appeal in contemporary philosophy and empirical psychology, it is fair to call this the Received View regarding the relation between habit and deliberation. I should stress, however, that this view has not been predominant throughout of history of philosophy and related disciplines (I shall come back to this in the following section). The Received View stems from a quite recent conceptualization of habit in empirical psychology, some aspects of which I have sketched above. Its influence largely reflects the impact of empirical psychology on current philosophical conceptions of the mind. ${ }^{10}$ This observation makes the examination of the credentials of the Received View all the more urgent.

\section{Against the Received View}

It is not very hard to show that the sorts of acts we call habitual in pre-theoretical discourse may involve conscious thought or deliberation. Surely, to say that Maya is in the habit of going to holidays in Sicily, or of visiting her parents at Christmas, is not to imply that she gives no thought at all about what to do before doing these things. But this fact would seem to be of limited significance in the present context. A defender of the Received View may acknowledge that there is a lax use of 'habit' in pre-theoretical discourse that does not imply the operation of automaticity. But she would suggest that we set this aside because it does not do any explanatory work, in either theoretical or pretheoretical contexts. The theoretically useful idea of habit is a disposition that explains an act: why an agent came to do something on a certain occasion. As Gardner puts it:

Definitions must be judged according to their usefulness for predicting, explaining and changing behaviour. The lay definition of 'habit' as frequent, regular or persistent behaviour is unsatisfactory because it offers no explanatory mechanism for these characteristics (...) (Gardner 2014, 278).

According to Gardner and other proponents of the Received View, the sole explanatory mechanism of habit is automaticity:

A psychological operationalisation of habit has emerged, which incorporates an explanatory mechanism: habits are actions that are frequently performed because they are initiated automatically (Gardner 2012, 32).

It is important to distinguish two different claims here. First, an act is habitual in a theoretically interesting sense only if the habit explains an act: why and/or how an agent did something on some occasion. Second, a habit can explain an act only if the act ensues from the operation of the relevant variety of automaticity. It is the second claim that is my target here. ${ }^{11}$

10 I would like to thank an anonymous reviewer for pressing this point.

11 Notice that the first claim is also open to dispute. It is not at all evident that a habit explains an 
Let us start by noticing an implication of the Received View. Since a habitual act necessarily ensues from automaticity, it is possible that an agent is in the habit of $a$-ing in $c$, that she $a$ 's in $c$ on some occasion, and yet that the act is not habitual properly speaking, because it does not ensue from the operation of automaticity. For example, suppose John is in the habit of going for a walk before breakfast. But suppose that for some reason John paused to deliberate about whether to do so this morning. Suppose John finally decides to do what he is in the habit of doing, and acts on this intention: he does for a walk. On the Received View, John's act is not really habitual-not manifestation of his habit. We may casually say that his going for a walk this morning was habitual, for the pre-theoretical conception of habit allows this. But properly speaking, the act was only in accidental accord with his habit. For the act was not directly elicited, 'triggered' or 'cued' directly by the circumstances, but ensued from deliberation. ${ }^{12}$ What makes it the case that an act is a manifestation of a habit is the obtaining of a suitable explanatory relation between the habit and the act. Otherwise an act is merely in accidental accord with her habit. And on the Received View the only way in which a habit can explain the act is by appeal to the operation of automaticity.

In what follows I shall argue that what the Received View fails to take into account is that there are various ways in which a habit can explain an act. The operation of automaticity is only one of them. So an act can be a manifestation of that habit, even when it ensues from conscious thought and deliberation. I shall consider certain sorts of case that serve to illustrate what is wrong with the Received View.

The first sort of case is this. Suppose John plays tennis on Sunday afternoons; he has been doing that for years. His habit is firmly entrenched in life, so he does not usually pause to deliberate. When the afternoon arrives, he just heads for the tennis club. But this Sunday evening John has been invited to a friend's birthday party. So John pauses to deliberate about what to do, weighting the pros and cons. John finally decides (forms an intention) to go and play tennis, and acts on that intention: he plays a game of tennis this Sunday evening as he usually does.

Our question is whether John's habit still plays a role in the explanation of his act. The answer to this question is affirmative. What goes on in the example above is that habit proposes or suggests - so to speak-the default course of action, or activates the relevant mental representation, but in view of the alternative course of action presented by the invitation, John has to make a choice between these two options. However, habit still plays a role, precisely because it constrains the options considered in deliberation. John did not consider all the other things he could do on that sunny Sunday evening. He

act only in terms of explaining how the act came about-the act's occurrence on a certain occasion. Pollard (2006b) argues that habit explanations are a form of constitutive explanation, "the sort of explanation we give when we explain something by saying that it is a part of -constitutes something else" (Pollard 2006b, 240). I set this aside because even if Pollard's claim is correct, it is not straightforwardly incompatible with the claim that the act ensues from automaticity. 
likes going the pub, or to visit the local museums, and so on. His habit prevents him from considering all the other good alternatives. ${ }^{13}$ For we may suppose that had John's best option was to go to the museum. Had he paused to consider all his options, he would have acknowledged this and would have acted accordingly. Thus whereas John's habit is an indispensible part of the explanation of what he does, and hence not merely in accidental accord with his habit, he still acts on intention formed in deliberation. Generally, when an agent considers refraining from manifesting a habit, this is because he becomes aware of a salient alternative. Typically, the agent will choose between these two options. Considering refraining from manifesting a habit does not typically involve re-considering afresh all the available courses of action, or even a suitable sub-set of them. So when the agent finally decides to do what he is in the habit of doing in deliberation, the habit still explains the act.

To see the point more clearly, contrast John's case with the case of Matt. Matt is not in the habit of playing tennis on Sunday evenings. But this Sunday Matt has been invited for a game of tennis by a good friend. Matt has several other options, which he carefully considers in deliberation, but he finally decides (forms an intention) to go and play tennis. Now John and Matt likewise act on an intention formed in deliberation. The key point here is that if we insist that John's act is not a manifestation of his habit because it ensues from deliberation, then we have obliterated the difference between the case of John and Matt. But there is an evident difference between these two cases, and even though we might disagree on how exactly to characterize it, it is clear that this difference is due to the fact that only John has the habit in question. In the case of John habit does play some role in the explanation of his act, for there were better options open to him, which were occluded by the force of habit. But in the case of James habit does not explain anything, if only because he does not have the habit in question. This suggests that John's going to play tennis on the occasion, while it ensues from deliberation, is not merely in accidental accord with his habit but a manifestation of it.

I am coming now to a different kind of explanatory relation between habit and act, a relation that-again-does not preclude deliberation. A habit can be formed only when one repeatedly finds oneself in a familiar environment. An environment includes other people, places, objects, social events, and much more besides. Some of these will be very

13 Verplanken, Aarts and Van Knippenberg claim that the results obtained in their experiments suggest that "habit in daily behaviours may lead to a narrow focus on the habitually chosen option, i.e. habit may limit the decision-maker's consideration set. (...) In other words, habit may be accompanied by less motivation to search out information, regardless of whether this information is unknown, and regardless of its importance." (Verplanken, Aarts and Van Knippenberg 1997, 556). In later research, Danner, Aarts, and de Vries (2007) examine how habit formation involves limiting the consideration of alternative courses of action by inhibiting the retrieval of possible alternatives from memory. Consequently, as a habit is gradually formed, relevant alternatives become more likely to be overlooked in deliberation. So one way to account for the case above is to suppose that while the invitation summons John to consider one alternative, the habit is still operative in inhibiting other alternatives, including the best one. But in such a case deliberation will still be required. So although research on habit provides the essentials for making sense of cases such as the ones described above, psychologists who take automaticity to be a defining feature of habit have failed to take such cases into account. 
important to an agent's life. So as a result of this familiarity, one tends to develop emotional bonds to other people, places, objects, social processes, and so on, as well as feelings of comfort, security, familiarity, affinity or intimacy with what one is well acquainted with on the basis of previous experience. By contrast, an unknown course of action might be regarded with a sense of reluctance, uncertainty, insecurity and even vulnerability. This is why creatures of habit like us gravitate towards familiar environments and people. The intimate relation between habit and feelings or emotions is a recurring theme in more historically oriented accounts of habit (Carlisle 2006; 2014). ${ }^{14}$ And it figures increasingly in the relevant research in psychology. ${ }^{15}$

When it is recognized that repeatedly doing something in certain circumstances (which include places and other sorts of environment, objects, people, etc.) promotes the formation of feelings of familiarity and attachment with circumstances, it is not hard to understand how the fact that one is in the habit of doing something can explain an act even though the act ensues from deliberation. For one thing, the emotional bonds forged by habituation may weigh in deliberation in favor of doing what one is in the habit of doing.

The second sort of case serves to illustrate these points. In this case the agent considers many available options in deliberation, but she still forms an intention to do what she is the habit of doing. Suppose Helen is in the habit of staying in some hotel when she visits London. She has done that again and again over the years. However, her friends have by now convinced her that other hotels offer better accommodation and services at this price range. Helen is about to book a room for the next trip. She pauses to take into account the considerations urged by her friends. Yet after pondering about which hotel to book, she decides to go to the one she usually goes. Her reasons are simply that she is

14 On this point it is worth quoting Carlisle in full: "The force of habit suggests a natural affinity with the known, and an aversion to the unknown. It often happens that in a new environment people quickly settle into a certain position. At the beginning of a conference, for example, you find a seat, either accidentally or by design, and then return to it (doggedly) at each new session, as if reassured by its familiarity. You may feel a stab of indignation to find someone in your place - that is, in an uncomfortable chair just like the others in the room. Or you return to the same table in a café, relieved to find it unoccupied. At the start of term, a class of students sit around a table, and without any compulsion or plan will often arrange themselves in the same way for the rest of the term. Like a loyal dog, habit loves what it knows, regardless of its inherent value" (Carlisle 2014, 38).

15 The relation between (repeated) exposure to certain circumstances and emotional bonds has been well documented (see Bornstein 1989 for a review of earlier literature). Recent research has explicitly addressed the more specific relation between habit and feelings of safety, confidence and comfort. One researcher sums up the results obtained as follows: "An examination of the influence of routine behaviour on people's feelings of safety, confidence, and well-being shows, as hypothesized, that these positive emotions increase with routine behaviour. (...) [R]outine enhances feelings of safety, confidence, and well-being in many aspects of everyday life" (Avni-Babad 2011, 223). See also Wood $(2017,10)$ and references therein. In the same vein, Wood, Quinn and Kashy claim that habitual behavior reduces the negative feelings of stress or loss of control which are associated with deliberating about a new course of action (Wood, Quinn \& Kashy 2002, 1283$4 ;$ 1294-5). Moreover, Wood $(2017,8-9)$ presents current research on 'social interaction habits', which are elicited by other people and specific social contexts. These include habits of interacting with people belonging to different social groups. As Wood explains, the emotional substratum involved in the formation and manifestation of such habits has the potential to contribute to our understanding of social discrimination and segregation practices. 
accustomed to it, she feels more confortable or 'at home'. Perhaps she also feels safer, even though she has been informed that the other hotels are situated in safer areas. In this case Hannah opts for this hotel on the basis of deliberation. But this does not mean that her habit is not part of a comprehensive explanation of her act. The considerations that account for her decision can only be properly appreciated in the light of her habit.

We can further support this point by contrasting Helen's case with the case of Sophie. Like Helen, Sophie is in the habit is staying in the same hotel when visiting London. Next month Sophie is invited at a conference in London, and is about to book a room. She has been informed that the organizer would propose a hotel to all speakers, and has already decided to book at whatever hotel the organizer would suggest. Luckily for Sophie, it turns out that is the hotel she is in the habit of staying. She is relieved to book at the hotel she usually stays, but this is pure coincidence. Had the organizer proposed a different hotel, she should have booked there.

The acts of Helen and Sophie acts likewise ensue from deliberation. Yet Helen's case is clearly distinct from Sophie's case. Sophie's overwhelming consideration has always been to stay in the hotel proposed by the organizer. This reason is not related to her habit, so Sophie's act is merely in accidental accord with her habit. This is not the case with Helen, however. So if we insist that Helen's act was not a manifestation of her habit because it ensues from deliberation, we would obliterate the differences between the case of Helen and Sophie. We would have failed to take into account that Helen's habit still explains why she acted as she did, and hence that her act is habitual, as opposed to Sophie's. This suggests that a comprehensive account of the distinctive kind or kinds of motivation and underlie habitual acts should include the emotional bonds the development of which is part of the relevant kind of habituation. A habit does not explain an act only as a direct automatic response to the circumstances one is faced with. Hence an act may be habitual-a manifestation of a habit-even when it ensues from deliberation.

The case of Helen points to a deeper problem with the Received View. It is a recurrent theme in the history of philosophy that habits are closely related to one's character. ${ }^{16}$ When we learn about someone's habits we learn a good deal of the kind of person he is, his affections, preferences and values. And this matters to explanation. It is often the case that a habit explains an act by informing us about the agent's preferences and values, and hence, if somehow obliquely, about her character. But this kind of explanation does not imply the absence of deliberation. Suppose Antony is in the habit of going to the opera on Saturday night, and did so last Saturday. But suppose Antony had other commitments, so he had to deliberate about whether to go or not. Does that mean that mentioning his habit has no explanatory import? When we learn about Antony's habit in this context, we learn about his values and preferences; he loves going to the opera; presumably he enjoys

16 For a historical survey, see Carlisle (2006). For a recent treatment of this theme see Pollard (2011). 
classical music and theatrics generally. But if Antony is that sort of person, this can hardly be irrelevant in explaining why he went to the opera last Saturday. Habit explanations often allow us to understand why an agent did something by pointing to the agent's preferences and values. (Notice that this does not exclude the operation of automaticity; but it does not imply it either). This is why learning about Antony's habit may render his act intelligible even if we know that he paused to deliberate.

I do not mean to suggest that character traits are nothing but habits. Still, the formation of a habit is often explained by a character trait, and conversely, the acquisition of a habit can contribute to the consolidation or attenuation of certain traits. For example, just as Antony's character accounts for his habit, shyness might lead a pupil to repeatedly take a certain seat in the classroom, which thereby develops into a habit, and that habit is henceforth expressive and constitutive of that trait. Conversely, one might set to cultivate healthy habits in order to combat one's unhealthy lifestyle, or try to cultivate habits of moderate behavior in order to ameliorate one's profligate character. The traditional idea of habituation does justice to this close relationship between habits and character. In Aristotelian ethics, to take a prominent example, habituation is a process that shapes, among other things, one's emotional and evaluative propensities. Habituation is the formation of character as a whole, which of course includes (and may start form) the acquisition of certain habits. But the Received View implies a very impoverished conception of habituation, as a process that merely involves the acquisition of automaticity, in the sense of doing something as a direct response to certain circumstances. This makes all the harder to account for the rich interconnections between habits and one's emotional and motivational make-up.

When we think about all the different sorts of things with respect to which we ascribe habits, we can see that we commonly assume this variety of explanatory relations between habits and acts. People would typically pause to think, even if briefly, about where to spend their holidays, about how to dress for an occasion, about which dish to cook, or about which record to play. These are simply not the sorts of things we typically do without any thought or deliberation, yet they are among the paradigm sorts of case that call for a habit explanation. I have suggested that habit may explain such acts to the extent that it highlights certain considerations in deliberation while it silences others. Thus by restricting habit explanations to acts that do not ensue from deliberation, the Received View unjustifiably narrows the scope of habit explanation and hence fails to do justice to the theoretical usefulness of the idea of habit.

This takes us back to Gardner's abomination of the 'lay definition' of habit. The above suggest that a more inclusive conception of habitual acts, which does not presuppose the absence of deliberation, has a role to play in the explanation and assessment of action. Perhaps there is a use of 'habit' in pre-theoretical discourse which implies 'no explanatory mechanism', in Gardner's words. But it is deeply erroneous to assume, as Gardner and many others seem to do, that the only mode of habit explanation on offer appeals to 
automaticity as a direct response to the circumstances which excludes deliberation. For this implies an impoverished idea of habit, which fails to do justice to its rich explanatory potential in theoretical and pre-theoretical contexts, as well as to its role in the history of thought.

\section{Conclusion}

I have started by presenting a rudimentary characterization of the idea of habit, which consists of three necessary conditions. I have suggested that these conditions largely accord with the essential features attributed to habit in current literature. There is an important difference, however: many philosophers, as well as the overwhelming majority of psychologists, also take automaticity to be an essential feature of habit. And they suppose that the variety of automaticity involved in habitual acts excludes deliberation, because habitual acts are direct responses to the circumstances. This is the Received View. I have argued against this view, that the idea of a propensity to do something in certain circumstances, a propensity acquired by habituation, does not explain an act only as a direct response to the circumstances-a form of explanation that excludes deliberation. Habit has a richer explanatory potential. I have illustrated different modes of habit explanation by considering certain types of case where habit serves to explain an act while the act ensues from deliberation. And I have suggested that this variety of acquired automaticity appealed to by the Received view is one outgrowth of habituation that is relevant to explanation, but not the only one. The view that habit essentially involves the absence of deliberation is bound to illicitly narrow the explanatory scope and hence the theoretical usefulness of the idea of habit.

\section{References}

Aarts H. \& Dijksterhuis A. 2000a. "Habits as Knowledge Structures: Automaticity in Goaldirected Behavior." Journal of Personality and Social Psychology 78:53-63.

Aarts H. \& Dijksterhuis A. 2000b. "On the Automatic Activation of Goal-Directed Behavior: The Case of Travel Habit." Journal of Environmental Psychology 20:75-82. Alvarez M. 2010. Kinds of Reasons: An Essay in the Philosophy of Action. Oxford: Oxford University Press.

Amaya S. 2013. "Slips.” Noûs 47:559-576.

Annas J. 2011a. Intelligent Virtue. New York: Oxford University Press.

Annas J. 2011b. "Practical Expertise." In J. Bengson \& M. A. Moffett (Eds.), Knowing How: Essays on Knowledge, Mind, and Action. New York: Oxford University Press (101-12). 
Anscombe G.E.M. 2000/1963. Intention. Cambridge, Massachusetts: Harvard University Press.

Avni-Babad D. 2011. "Routine and Feelings of Safety, Confidence, and Well-being." British Journal of Psychology 102:223-244.

Bargh J. 1997. "The Automaticity of Everyday Life." In R. Wyer (Ed.), The Automaticity of Everyday Life. New York: Lawrence Erlbaum (1-62).

Bargh J. 1990. "Auto-motives: Preconscious Determinants of Social Interaction”. In E. T. Higgins \& R. M. Sorrentino (Eds.), Handbook of Motivation and Cognition: Foundations of Social Behavior Vol. 2. New York: Guilford (93-130).

Bargh J. 1994. "The Four Horsemen of Automaticity: Awareness, Intention, Efficiency, and Control in Social Cognition." In R. Wyer \& T. Srull (Eds.), Handbook of Social Cognition. Hillsdale, New Jersey: Lawrence Erlbaum (1-40).

Bargh J. \& Gollwitzer P. M. 1994. "Environmental Control of Goal-directed Action: Automatic and Strategic Contingencies between Situations and Behavior." In W. Spaulding (Ed.), Nebraska Symposium on Motivation Vol. 41. Lincoln: University of Nebraska Press (71-124).

Bargh J. 1989. "Conditional Automaticity: Varieties of Automatic Influence in Social Perception and Cognition." In J. S. Uleman and J. A. Bargh (Eds.), Unintended Thought. New York: The Guilford Press (3-51).

Bornstein R. F. 1989. "Exposure and Affect: Overview and Meta-analysis of Research, 1968-1987." Psychological Bulletin 106:265-289.

Brett N. 1981. "Human Habits.” Canadian Journal of Philosophy 11:357-376.

Carlisle C. 2005. "Creatures of habit: The Problem and the Practice of Liberation". Continental Philosophy Review 38:19-39.

Carlisle C. 2014. On Habit. London: Routledge.

Cooper R. \& Shallice T. 2006. "Hierarchical Schemas and Goals in the Control of Sequential Behavior." Psychological Review 113:887-916.

Danner U. N., Aarts H., \& de Vries N. K. 2007. "Habit Formation and Multiple Means to Goal Attainment: Repeated Tetrieval of Target Means Causes Inhibited Access to Competitors." Personality and Social Psychology Bulletin 33:1367-79.

Dezfouli A., Lingawi N. W., \& Balleine B. W. 2014. "Habits as Action Sequences: Hierarchical Action Control and Changes in Outcome Value." Philosophical Transactions of the Royal Society B 369:1655.

Di Nucci E. 2013. Mindlessness. Newcastle upon Tyne: Cambridge Scholars Press. Enc B. 2003. How We Act. New York: Oxford: Clarendon Press.

Fara M. 2005. “Dispositions and Habituals.” Noûs 39:43-82.

Gardner B. 2015. "A Review and Analysis of the Use of 'Habit' in Understanding, Predicting and Influencing Health-related Behavior." Health Psychology Review 9:277-95 
Gardner B., Abraham C., Lally P., \& de Bruijn G. J. 2012. "Towards Parsimony in Habit Measurement: Testing the Convergent and Predictive Validity of an Automaticity Subscale of the Self-report Habit Index." International Journal of Behavioral Nutrition and Physical Activity 9:102.

Gardner B., de Bruijn G. J., \& Lally P. 2011. "A Systematic Review and Meta-analysis of Applications of the Self-report Habit Index to Nutrition and Physical Activity Behaviours". Annals of Behavioral Medicine 42:174-187.

Gardner B. 2012. "Habit as Automaticity, Not Frequency." European Health Psychologist 14:32-36.

Graybiel A. M. 2008. "Habits, Rituals, and the Evaluative Brain." Annual Review of Neuroscience 31:358-87.

Hornsby J. 1980. Actions. London: Routledge and Kegan Paul.

James W. 1981. The Principles of Psychology. Harvard University Press.

Maddux J. E. 1997. "Habit, Health and Happiness." Journal of Sport \& Exercise Psychology 19:331-46.

Moors A. \& De Houwer J. 2006. "Automaticity: A Conceptual and Theoretical Analysis". Psychological Bulletin 132:297-326.

Moors A. \& De Houwer J. 2007. "What is Automaticity? An Analysis of Its Component Features and Their Interrelations." In J. A. Bargh (Ed.), Social Psychology and the Unconscious: The Automaticity of Higher Mental Processes. New York: Psychology Press (11-50).

Neal D. T. \& Wood W. 2009. "Automaticity In Situ and in the Lab: The Nature of Habit in Daily Life." In E. Morsella, J. A. Bargh, \& P. M. Gollwitzer (Eds.), The Oxford Handbook of Human Action. New York: Oxford University Press (428-42).

Nilsen P., Roback K., Broström A., \& Ellström P. E. 2012. “Creatures of Habit: Accounting for the Role of Habit in Implementation Research on Clinical Behaviour Change." Implementation Science 7:53.

Norman D. 1981. “Categorization of Action Slips.” Psychological Review 8:1-15.

Orbell, S., \& Verplanken, B. 2010. "The Automatic Component of Habit in Health Behavior: Habit As Cue-contingent Automaticity." Health Psychology 29:374-83.

Ouellette J. A., \& Wood W. 1998. "Habit and Intention in Everyday Life: The Multiple Processes By Which Past Behavior Predicts Future Behavior." Psychological Bulletin 124:54-74.

Owens D. 2008. "Deliberation and the First Person." In A. E. Hatzimoysis (Ed.), SelfKnowledge. Oxford: Oxford University Press (261-277).

Pollard B. 2006a. "Explaining Actions with Habits.” American Philosophical Quarterly 43:57-69.

Pollard B. 2006b. "Actions, Habits and Constitution." Ratio 19:229-48.

Pollard B. 2008. Habits in Action. Saarbrücken: Vdm Verlag Dr. Mueller. 
Pollard B. 2011. "Identification, Psychology, and Habits." In J. Aguilar, A. Buckareff \& K. Frankish (Eds.), New Waves in Philosophy of Action. New York: Palgrave Macmillan (81-97).

Reason J. 1990. Human Error. New York: Cambridge University Press.

Ryle G. 2009. The Concept of Mind. London and New York: Routledge $60^{\text {th }}$ Anniversary Edition.

van t'Riet J., Sijtsema S. J., Dagevos H., \& de Bruijn G.-J. 2011. “The Importance of Habits in Eating Behavior. An Overview and Recommendations for future research." Appetite 57:585-96.

Verplanken B. \& Wood W. 2006. "Interventions to Break and Create Consumer Habits." Journal of Public Policy \& Marketing 25:90-103.

Verplanken B., Aarts H., \& Van Knippenberg A. 1997. "Habit, Information Acquisition, and the Process of Making Travel Mode Choices." European Journal of Social Psychology 27:539-60.

Wood W. \& Neal D. T. 2007. "A New Look at Habits and the Habit-Goal Interface." Psychological Review 114: 843-63.

Wood W. \& Runger D. 2016. "Psychology of Habit." Annual Review of Psychology 37:289314.

Wood W., Labrecque J., Lin P., \& Rünger D. 2014. "Habits in Dual-Process Models." In J. Sherman, B. Gawronski, \& Y. Trope (Eds.), Dual Process Theories of the Social Mind. New York: Guilford Press (371-85).

Wood W., Quinn J. M., \& Kashy D. A. 2002. "Habits in Everyday Life: Thought, Emotion, and Action." Journal of Personality and Social Psychology 83:1281-97

Wu W. 2011. "Confronting Many-Many Problems: Attention and Agentive Control". Noûs 45:50-76.

Wu W. 2013. "Mental Action and the Threat of Automaticity". In A. Clark, J. Kiverstein, \& T. Vierkant (Eds.), Decomposing the Will. New York: Oxford University Press (244-61). 


\title{
Christos Douskos
}

(Athens)

\section{Deliberation and Automaticity in Habitual Acts}

\begin{abstract}
Most philosophers and psychologists assume that habitual acts do not ensue from deliberation, but are direct responses to the circumstances: habit essentially involves a variety of automaticity. My objective in this paper is to show that this view is unduly restrictive. A habit can explain an act in various ways. Pointing to the operation of automaticity is only one of them. I draw attention to the fact that acquired automaticity is one outgrowth of habituation that is relevant to explanation, but not the only one. Habituation shapes our emotional and motivational make up in ways that affect deliberation itself. Hence mentioning a habit might be indispensable in explaining an act which nevertheless ensues from deliberation. The view that habitual acts are direct responses to the circumstances implies an impoverished conception of habit, which fails to do justice to its rich explanatory potential in theoretical and pre-theoretical contexts, as well as to its role in the history of philosophy.
\end{abstract}

Keywords: habit; deliberation; automaticity; action explanation.

Ethics in Progress (ISSN 2084-9257). Vol. 9 (2018). No. 1, Art. \#2, pp. 25-43.

Creative Commons BY-SA 3.0

Doi: 10.14746/eip.2018.1.2 